\title{
Effect of Mechanical Stirring on the Preparation of High Visible Light Active N S Co-Doped Nano Titania: Synthesis and Characterisation
}

\author{
Rajesh K. M. ${ }^{1,2}$, Sugunan S. ${ }^{1}$ \\ ${ }^{I}$ Department of Applied Chemistry, Cochin University of Science and Technology, Cochin-22,Kerala, India. \\ ${ }^{2}$ Post Graduate and Research Department of Chemistry, Sree Narayana College, Kannur-670007, Kerala, \\ India.
}

\begin{abstract}
A highly visible light responsive $N, S$ non-metals co-doped nano titania are prepared through simple modification of sol-gel method called sol-gel precipitation. Characterisation techniques such as XRD, UV-Vis. DRS, CHNS Elemental analysis, BET surface area, TEM and XPS demonstrated the good dispersion properties of $\mathrm{N}$ and $\mathrm{S}$ on $\mathrm{TiO}_{2}$. Photocatalytic degradation studies are carried out with aqueous solution of 2,4dichlorophenoxy-acetic acid (2,4-D) in Visible as well as UV light irradiation. Comparison of relative photo catalytic efficiencies demonstrated that $N, S$ co-doped photocatalyst exhibited higher activity in visible than $U V$ light. More than $90 \%$ of the herbicide degraded within one-hour irradiation with catalyst amount $3 \mathrm{~g} / \mathrm{L}$. In addition, the high visible light activity of the catalyst is mainly correlated to its method of preparation which is highly depends on effect of mechanical stirring and stirring time.
\end{abstract}

Key words: $\mathrm{NS}$ co-doped nano $\mathrm{TiO}_{2}$, Sol-gel precipitation, Photocatalysis, Visible light Absorption, 2,4-Dichlorophenoxyacetic acid.

\section{Introduction}

Now-a-days titanium dioxide is a well-known photocatalyst for the removal or degradation of organic pollutants [1]. Honda and Fujishima have extensively studied titania as a photocatalyst since the discovery of its photosensitization effect in 1972 [2]. Due to its strong photo-oxidizing potential, high chemical stability, nontoxicity, and low cost, titanium dioxide has been made into various forms, such as nano powders, nano rods, nano fibers, nano tubes, colloids, films and applied into environmental cleaning applications [3]. However, its activity was limited to UV region of the solar source due to its wide band gap of $3.2 \mathrm{eV}$, (anatase). The solar region contains around $5 \%$ of UV light and 40-45\% Visible light. Therefore, in order to use solar energy effectively, it is essential to extend the absorption region of titania into visible region. Many attempts were reported by various research groups to bring the activity of titania into visible region such as doping with metals, non-metals, coupling with other semiconductors, sensitizing titania with other colorful inorganic or organic compounds [4]. However, it was noted that the anionic dopant species were found to be better than others with respect to the stability of the doped materials, photocatalytic efficiency, and ease of the doping process [5]. Many researchers successfully reported the visible light active non-metal doped titania catalyst with B, C, N, F, $\mathrm{P}, \mathrm{S}, \mathrm{Cl}, \mathrm{Br}$ and I as the dopants. Undeniably, the non-metal doped $\mathrm{TiO}_{2}$ photocatalyst is a hot research topic, and it opens up a new possibility for the development of solar light induced photocatalytic materials by codoping with two non-metals such as C-N, C-F, N-S, N-F, N-P etc [6-16]. Among this N, S co-doped titania is most studied. Most of the studies for the preparation of N,S co-doped system require high temperature, expensive precursors or other expensive technical instrumental facilities such as autoclave, sonicator, vapour depositor, microwave producers etc. However, it was noted that the photocatalytic activity mainly depends on its method of preparation [1] along with the surface area, phase purity, crystallinity, shift in band gap, presence of other impurities etc.

The presence of chloro organic compounds in environment is one of the greatest problems for human future. 2, 4-Dichlorophenoxyacetic acid (2,4D), most commonly used herbicide in controlling broadleaf weeds and other vegetation, belongs to one such class of compound. There are approximately 1500-registered products that contain 2, 4-D in their composition and more than 70 million pounds of this active ingredient are distributed annually. These compounds tend to accumulate in water and soil, which is the reason why they are termed as recalcitrant or refractory compounds. Important methods reported for the elimination of 2,4-D from aqueous solution include microbial, chemical and photochemical processes. Photocatalysis is a subject of increasing interest as a method for wastewater treatment. In photocatalysis, oxidation occurs by the attack of $\mathrm{OH}^{*}$, which has a rate constant much higher than the normal oxidation rate constant, using air as the oxidant [17]. 
There are many studies cited in literature for the photocatalytic removal or degradation of 2, 4-D with varying degree of success [1, 17-21]. However, most of them require a long time irradiation, use of UV light, and very low concentration of the reactant.

In this study, we use a modified sol-gel method with a simple mechanical stirring of the reaction mixture for the control of its surface characteristics and activity properties. However, to our knowledge, there are only few reports on the high percentage photocatalytic degradation of 2,4-D using anion co-doped titania via sol-gel method. Thus, the present work is aimed at a simple route for synthesis of highly visible light responsive N,S co-doped titania through sol-gel precipitation method. The catalysts were characterized by various techniques XRD, UV-Vis. DRS, CHNS elemental analysis, BET surface area, TEM, and XPS. The photocatalytic ability of the prepared samples in Visible and UV light are studied for the degradation of organic pollutant-herbicide- 2,4-D and the results are compared with pure titania prepared in the same manner and one of the commercial anatase titania.

\subsection{Catalyst Preparation}

\section{Experimental Section}

i) Pure Titania: For the preparation of pure titania $0.96 \mathrm{~g}$ of Titanium tetraisopropoxide was dissolved in $7.85 \mathrm{~g}$ of isopropyl alcohol and to the mixture; $100 \mathrm{ml}$ of distilled water was added drop wise with vigorous stirring at room temperature, it was aged for one day, dried below $70{ }^{\circ} \mathrm{C}$ and calcined at $400{ }^{\circ} \mathrm{C}$ for 4 hours. The sample denoted as $\mathrm{L}-\mathrm{TiO}_{2}$

ii) N, S co-doped titania: A $100 \mathrm{ml}$ aqueous solution of $1.0 \%(\mathrm{w} / \mathrm{v})$ thiourea was used as dopant source. The sample denoted as $\mathrm{NS}^{-\mathrm{TiO}_{2}}$. The commercial titania was obtained from Sigma Aldrich having $100 \%$ anatase denoted as $\mathrm{A}-\mathrm{TiO}_{2}$.

\subsection{Characterization}

The X-ray diffraction (XRD) patterns were recorded using Bruker AXS D8 advance X ray Diffractometer with Ni filtered $\mathrm{Cu} K \alpha$ radiation $(\lambda=0.15406 \mathrm{~nm})$. The intensities were obtained in the $2 \theta$ range $10-70^{\circ}$. The crystallite size was determined from the broadening of the major peak in the XRD spectrum using the Scherrer equation. $\quad D=K \lambda / \beta \operatorname{Cos} \theta$. Where $D$ is the crystallite size, $K=0.9$ is a constant, $\lambda$ is the $X$-ray wavelength, $\beta$ is full width half maximum of the major peak and $\theta$ is the diffraction angle. The UV-Visible diffuse reflectance spectra (UV-Vis.DRS) were recorded in the range of 200-900 nm on a Labomed UVD-500 UV-Visible Double beam spectropho-tometer equipped with an integrating sphere assembly, using $\mathrm{BaSO}_{4}$ as reflectance standard. The percent of nitrogen and sulphur in the sample were determined using the Elementar Vario EL III CHN analyzer. The Transmission Electron Microscopy (TEM) images were recorded Jeol 3010 ultrahigh resolution analytical electron microscope. A sonicated solution of the sample in alcohol, which evaporates on the TEM grid to form a dry film, was prepared. The X-ray Photoelectron Spectra (XPS) were recorded in an indigenously developed electron spectrometer equipped with Thermo VG Clamp-2 Analyser and a $\mathrm{Mg} \mathrm{K} \alpha \mathrm{X}$-ray source $(1253.6 \mathrm{eV}, 30 \mathrm{~mA} \times 8 \mathrm{kV})$. A thin sample wafer of $12 \mathrm{~mm}$ in diameter was used in these studies. Absolute binding energy of $\mathrm{C} 1 \mathrm{~s}$ peak at $284.6 \mathrm{eV}$ was used as an internal reference. The BrunauerEmmett-Teller (BET) surface area of the samples was measured using Micromeritics Tristar 3000 surface area and porosity analyzer. The samples were activated at $90{ }^{\circ} \mathrm{C}$ for $30 \mathrm{~min}$. and degassed at $350{ }^{\circ} \mathrm{C}$ for 4 hours under nitrogen flow.

\subsection{Photocatalytic Activity}

The photocatalytic experiments were carried out in an Oriel Uniform illuminator of $100 \mathrm{~W}$ Xe ozone free light sources with filter of $280-400 \mathrm{~nm}$ and $420-630 \mathrm{~nm}$ at room temperature. About $10 \mathrm{ml}$ of $10^{-4} \mathrm{M}$ aqueous solution of 2, 4-D was taken and $0.03 \mathrm{~g}$ of the catalyst was added. The solution stirred under dark for 30 minutes to achieve adsorption-desorption equilibrium and illuminated for one hour. After irradiation, the mixture centrifuged and analyzed using HPLC [Luna ODS-2 C-18 column of $25 \mathrm{~cm}, 5 \mu \mathrm{m}$ ] with mobile phase of methanol/water/trifluoroacetic acid $(1.0 \mathrm{ml} / \mathrm{min})$ in the ratio of 70:30:0.08 with UV detection at $230 \mathrm{~nm}$. Studies involve the change in amount of catalyst, different amount of dopant loading, comparison of percent degradation in visible and UV region, adsorption and kinetics studies. The photocatalytic ability of the catalyst reported as the percent degradation using the equation.

Percent of Degradation $=\left[\mathrm{C}_{\mathrm{o}}-\mathrm{C}\right] \times 100 / \mathrm{C}_{\mathrm{o}}$.

Where $\mathrm{C}_{\mathrm{o}}$ and $\mathrm{C}$ are the concentration of 2,4-D before and after irradiation.

\subsection{Catalyst Preparation}

\section{Results and Discussion}

In this section, we discuss the effect of mechanical stirring for the optimization of catalyst with very good morphology and activity. Normally in sol-gel method, the morphological properties can be controlled by 
Effect of mechanical stirring on the preparation of high visible light active N S co-doped nano titania:

the addition of acids or bases, which depends on the point of zero charge of the particles. In present study, we do not add any acid or bases; instead, we add the aqueous solution of the dopants dropwise. The presence of aqueous medium facilitates easy precipitation of precursor molecules through hydrolysis. As precipitation occurs rapidly, the morphological properties and activity of the catalyst reduced. In order to avoid the formation of precipitate we introduce a vigorous stirring of the solution mixture. The vigorous stirring helps to control the morphological properties through formation of a sol without formation of the precipitate. Vigorous stirring permits the formation of fine particles and prevent the degree of agglomeration. The particle-particle interaction is limited during the stirring. We also observe the contribution of stirring time towards the higher activity. In our study, we optimized the stirring time of 12 hours. And above this the activity was decreased (not shown here). As the time of stirring increases, the stability of doped species on the titania framework decreases. As the stability of dopant species decreases, it decreases the activity of the modified catalyst in visible light irradiation.

\section{2. $X$-ray Diffraction}

Fig. 1 shows the XRD spectra. All the samples showed a major peak at $2 \theta$ of $25.4^{0}$ which is the characteristic of (101) plane of anatase phase. The absence of other major peaks confirmed the presence of anatase phase only. All catalysts showed more or less equal 'd'spacing value (for the major peak) which indicated the stabilization of anatase phase by the dopant. The slight changes may be due to the lattice expansion along c- axis because of anion incorporation [10]. Moreover, the dopants also enhance the crystalline nature. The average crystallite size calculated from the broadening of (101) XRD peaks of anatase using the Scherrer equation are shown in Table 1. The broadening of the peaks in the prepared samples indicated that the particles size has decreased compared to commercial sample [22-25]. Peaks due to the dopants were absent. This revealed that the structure of titania is not affected by the incorporation of the dopants.

\section{3. $U V$-Visible diffuse reflectance spectra}

UV Visible Diffuse reflectance spectra of the samples are shown in Fig. 2. The absorption edges obtained as the wavelength of the onset of the spectrum is converted to bandgap [11] using one of the forms of Kubelka-Munk function $(\mathrm{Eg}=1239.8 / \lambda)$ as shown in Table 1. Incorporation of dopants $\mathrm{N}$ and $\mathrm{S}$ is indicated by the colour change of the samples from white to pale yellow. The doped samples showed a red shift in absorption maximum and possessed two absorption edges compared to pure titania. The absorption edges were related to original structure and doped structure of titania [15]. The red shift was due to the impurities incorporated into titania framework which resulted in narrowing the bandgap by mixing their $\mathrm{p}$ states with $\mathrm{O} 2 \mathrm{p}$ orbitals.

\subsection{BET-Surface area measurements}

The specific surface area of the samples reported in Table 1, showed a noticeable increase compared to $\mathrm{A}-\mathrm{TiO}_{2}$. This is one of the advantages of the sol-gel method [26]. The vigorous stirring of the reaction mixture allows the formation of fine particles that helps increase the surface area. The presence of dopant disturbed the hydrolysis-condensation reactions of the precursor and got well dispersed on the surface of titania which resulted in the increase of specific surface area.

\subsection{Transmission electron microscopy (TEM) studies}

The TEM, Selected area electron diffraction (SAED) and High resolution TEM images of catalyst NS$\mathrm{TiO}_{2}$ shown in Fig. 3a-c. The TEM images showed that particle size of $\mathrm{NS}^{-\mathrm{TiO}_{2}}$ is in the range $7-13 \mathrm{~nm}$. From the HRTEM and SAED the d value corresponding to the (101) plane of the anatase phase was calculated. The particle size and anatase (101) plane obtained from the TEM study showed very good agreement with XRD results. The powders found to be fine and slightly agglomerated.

\subsection{X-ray Photoelectron Spectra studies}

Fig. 4a-d. shows the XPS spectra of $\mathrm{NS}^{-\mathrm{TiO}_{2}}$. The atomic concentration derived from the XPS data presented in Table 2. For oxygen the 1s XPS spectra was de-convoluted using Gaussian multi-peak fitting program and peak area at $529.3 \mathrm{eV}$ was taken for atomic ratio calculation purpose. Areas for corresponding peaks were divided by the sensitivity factors in these calculations. At some places, C 1s peak with binding energy value of $284.8 \mathrm{eV}$ was referred as standard value for the surface adventitious carbon. Thus, the binding energy values are reported by including this correction with an increase of $0.2 \mathrm{eV}$.

The Ti 2p XPS spectrum (Fig. 4a) showed two peaks, one at 458.4 and $464.1 \mathrm{eV}$. These were assigned to the Ti $2 p_{3 / 2}$ and Ti $2 p_{1 / 2}$ states. These doublet peaks were due to the spin-orbit splitting of Ti $2 p$ [27]. The above values corresponded to the (IV) oxidation state of Ti. Thus in the prepared samples titanium is in (IV) oxidation state with stable Ti-O bond. For the pure titania these peaks are observed at 458.9 and $464.7 \mathrm{eV}$ respectively, which were contributions from O-Ti-O in $\mathrm{TiO}_{2}[24,28,29]$. The binding energy shifts were smaller 
for the doped samples. These shifts of Ti core level signal, which were attributed to Ti 2p peaks of Ti-O-N linkage, suggested the successful incorporation of the dopant into the titania lattice.

The O 1s XPS spectrum (Fig. 4b) showed a strong peak at $529.4 \mathrm{eV}$ corresponding to bulk oxygen bonded to titanium. There are two weak shoulders, one at $531 \mathrm{eV}$ due to oxygen attached to $\mathrm{N}$ and another weak shoulder at higher binding energy of $532.2 \mathrm{eV}$ due to the incorporation of $\mathrm{S}_{\text {as }} \mathrm{SO}_{4}{ }^{2-}$. The weak shoulder at higher binding energy was also associated with hydroxyl groups adsorbed on the $\mathrm{TiO}_{2}$ surface.

The S 2p XPS spectrum (Fig. 4c) showed a peak at $168.5 \mathrm{eV}$ corresponding $\mathrm{S} 2 \mathrm{p}_{3 / 2}$ state. Ohno and Wang reported that the peak of $\mathrm{S} 2 \mathrm{p}$ at $168.0-170.0 \mathrm{eV}$ corresponds to the $\mathrm{S}$ atom incorporated as cation in the form of $\mathrm{S}(\mathrm{VI})$ in titania network and peak at $160.0-163.5 \mathrm{eV}$ corresponds to $\mathrm{S}$ atom as $\mathrm{S}^{2-}$ by anionic replacement of $\mathrm{O}$ from titania lattice $[27,30]$. Thus the result indicated that the $\mathrm{S}$ in $\mathrm{S}(\mathrm{VI})$ state (as $\mathrm{SO}_{4}{ }^{2-}$ ). These sulphate ions can form $\mathrm{S}=\mathrm{O}$ and $\mathrm{S}-\mathrm{O}-\mathrm{S}$ bonds on the $\mathrm{TiO}_{2}$ surface, creating unbalanced charge on $\mathrm{Ti}$ and vacancies/defects in the titania network.

The N 1s XPS spectrum (Fig. 4d) showed a peak at $400.2 \mathrm{eV}$. The assignment of the XPS peak of $\mathrm{N} 1 \mathrm{~s}$ has been under debate, and controversial hypotheses have been provided, since the preparation methods, conditions and source of dopant largely affect N XPS spectral features. Asahi et al. [5] reported atomic beta N peak at $396 \mathrm{eV}$ corresponding to substitutional N. Most researchers also agreed N 1s peak at 396-397.5 eV corresponding to $\mathrm{N}$ atoms which existed as Ti-N-Ti in titania network [24,28,29,31]. Viswanath et al. [15] and Ma et al. [31] supported the above and assigned the peak at 398-399 eV to O-Ti-N linkage in the crystalline $\mathrm{TiO}_{2}$ lattice. Some researchers reported that the $\mathrm{N} 1 \mathrm{~s}$ peak at $400-402 \mathrm{eV}$ corresponds to molecularly adsorbed nitrogen in its oxidized state, which exists as Ti-O-N, and/or Ti-N-O linkages in titania network [24,28,29,3134]. Di Valentin et al. [35] have reported a significant advance toward the clarification of the above issues by means of electron paramagnetic resonance spectroscopy measurements and density functional theory calculations. They reported two types of $\mathrm{N}$ species in $\mathrm{N}^{-\mathrm{TiO}_{2}}$. Their spin-Hamiltonian parameters were consistent with calculations for both substitutional and interstitial $\mathrm{N}$ impurities. Thus our results indicates a peak at $400.2 \mathrm{eV}$ can be assigned to the interstitial $\mathrm{N}$ bound to one lattice oxygen as Ti-O-N, in which the $\mathrm{S}$ atom is incorporated as $\mathrm{S}(\mathrm{VI})$ which is assigned to the $\mathrm{SO}_{4}{ }^{2-}$ adsorbed on the surface.

\subsection{Photocatalytic activity}

Due to the shift of absorption edge into the visible region, the modified catalyst should be photocatalytically active under visible light irradiation. The photocatalytic ability of the prepared samples were evaluated by the degradation of the herbicide 2,4-dichlorophenoxyacetic acid at room temperature. The percentage degradation of 2,4-D against the amount of catalyst shown in Fig. 5a. The Photocatalytic degradation of 2,4-D initially increases with increase of catalyst amount and shows a maximum of $90.7 \%$ with one hour irradiation and a catalyst amount of $3 \mathrm{~g} / \mathrm{L}$, after that there is no significant change. As the quantity of catalyst increases, the active site also increases which enhance the adsorption and increases the activity. Further increase of the amount of catalyst resulted in the increase of the active site, but the concentration of pollutants remains constant, as a result, the photo-excited species recombined easily and decreases the activity.

The photocatalytic degradation of 2,4-D against the amount of dopant source is shown in Fig. 5b. The percent of degradation increases with increase of amount of dopant source and reaches a maximum with dopant source amount of $1 \%(\mathrm{w} / \mathrm{v})$ after that its decreases. Further increases of dopant source concentration resulted in shielding the active site of titania, which leads to the decrease of absorption of light by the catalyst, subsequently decrease the surface concentration of photo excited species available for further reactions hence decrease the activity. The kinetics study (percent degradation against time) shows that (Fig.5c) photocatalytic degradation increases with increases the time of irradiation.

Table 3 shows comparison results of activities of NS-TiO2, Pure titania and commercial titania in Visible light, UV light and without light irradiation. Commercial and pure titania showed more degradation activity in UV light while the N,S co-doped catalyst showed higher activity in visible light. The N,S co-doped system showed more than $90 \%$ degradation within one-hour irradiation in visible region. The presence of dopant impurities in the $\mathrm{TiO}_{2}$ lattice lead to narrow the band gap by mixing their $\mathrm{p}$ orbitals with the $\mathrm{O} 2 \mathrm{p}$ states [5]. This could be the reason for the shift of UV absorption maximum to visible region. The presence of impurities induce oxygen vacancies (F-type colour centre), which correlate the AB3 type absorption bands [36] and resulted in an improved visible light activity by mixing their $\mathrm{p}$ orbitals with $\mathrm{O} 2 \mathrm{p}$ states of the valance band. Higher surface area and smaller particle size could have also contributed to the photocatalytic activity by favoring the 2,4-D adsorption on the catalyst.

\section{Conclusions}

We were successful to synthesize visible light responsive anatase N,S co-doped nano crystalline titania through sol-gel precipitation method. The mechanical stirring and its duration helps the catalysts with optimized morphological and activity properties. The XRD characterization showed that particles were crystalline in anatase phase, these are further confirmed by TEM analysis. The particle size $(7-13 \mathrm{~nm})$ obtained from TEM 
Effect of mechanical stirring on the preparation of high visible light active N S co-doped nano titania: showed very good agreement from XRD. The XPS and CHN analysis confirmed the incorporation of dopants N and $\mathrm{S}$ in titania lattice. The XPS showed that chemical nature of dopant such as $\mathrm{N}$ existed as Ti-O-N and $\mathrm{S}$ existed as S (VI) cation. UV Visible DRS spectrum showed that the absorption edges of doping catalysts shifted to visible region, which lead to narrowing of band gap. The photo catalytic activities of the samples were evaluated by the degradation of the herbicide 2,4dicholorophenoxyacetic acid. More than $90 \%$ of the herbicide was degrade within one-hour irradiation of visible light with catalyst amount of $3 \mathrm{~g} / \mathrm{L}$ of N,S co-doped system. The higher activity is due to the presence of synergetic effect of two impurities (both $\mathrm{N}$ and $\mathrm{S}$ ) in their lattice, which are responsible for consistent reduction of band gap.

\section{ACKNOWLEDGEMENT}

The authors are gratefully acknowledging the financial support given by the Board of Research in Nuclear Science (BRNS) (No. 2006/37/34/BRNS), Department of Atomic Energy (DAE), and Government of India. We are also gratefully acknowledging the analytical facility provided by SAIF, Cochin University of Science and Technology and SAIF, IIT Chennai.

\section{References}

[1] F. Galindo, R. Gomez, M. Aguilar, J. Mol. Catal. A: Chem. 281 (2008) 119-225.

[2] K. Honda, A. Fujishima, Nature 238 (1972) 37-38.

[3] P.G. Wu, C.H. Ma, J.K. Shang, Appl. Phys. A. 81 (2005) 1411-1417.

[4] X. Chen, S.S. Mao, Chem. Rev. 107 (2007) 2891-2959.

[5] R. Asahi, T. Morikawa, T. Ohwaki, K. Aoki, Y. Taga, Science 293 (2001) 269-271.

[6] F. Wei, L. Ni, P. Cui, J. Hazard. Mat. 156 (2008) 135-140.

[7] H. Liu, L. Gao, J. Am. Ceram. Soc. 87 (2004) 1582-1584.

[8] S. Zhang, L. Song, S. Zhang, D. Sun, B. Chen, React. Kinet. Catal. Lett. 97 (2009) 199-205.

[9] Y. Xie, Q. Zhao, X.J. Zhao, Y. Li, Catal. Lett. 118 (2007) 231-237.

[10] L. Lin, R.Y. Zheng, J.L. Xie, Y.X. Zhu, Y.C. Xie, Appl. Catal. B: Environ. 76 (2007) 196-202.

[11] S. Yin, M. Komatsu, Q. Zhang, F. Saito, T. Sat, J. Mater. Sci. 42 (2007) 2399- 2404.

[12] Y. Xie, X. Zhao, J. Mol. Catal. A: Chem. 285 (2008) 142-149.

[13] M. Lim, Y. Zhou, B. Wood, Y. Guo, L. Wang, V. Rudolph, G. Lu J. phys. Chem. C. 112 (2008) 19655-19661.

[14] H.A. Seibel II, P. Karen, T.R. Wagner, P.M. Woodward, J. Mater. Chem. 19(2009) 471-477.

[15] S. Yin, K. Ihara, Y. Aita, M. Komatsu, T. Sato, J. Photochem.Photobiol. A: Chem. 179 (2006) 105-114.

[16] J. Yu, M. Zhou, B. Cheng, X. Zhao, J. Mol. Catal. A: Chem. 246 (2006) 176-184.

[17] S.P. Kamble, S.P. Deosarkar, S.B. Sawant, J.A. Moulijn, V.G. Pangarkar, Ind. Eng. Chem. Res. 43 (2004) 8178-8187.

[18] R.R. Giri, H. Ozaki, S. Taniguchi, R. Takanami, Environ. Sci. Technol. 5 (2008) 17-26.

[19] X. Zhang, H. Liu, W. Li, G. Cui, H. Xu, K. Han, Q. Long, Catal. Lett. 125 (2008) 371-375.

[20] K. Djebbar, A. Zertal, T. Sehili., Environ. Technol. 27 (2006) 1191-1197.

[21] M. Alvarez, T. Lopez, J.A. Odriozola, R.D. Gonzalez, J. Nanosci. Nanotechnol.8 (2008) 6414-6418.

[22] K. M. Reddy, B. Baruwati, M. Jayalakshmi, M. MohanRao, S.V. Manorama, J. Solid State Chem. 178 (2005) $3352-3358$.

[23] H-L Qin, G-B Gu, S. Liu, C. R. Chimie 11 (2008) 95-100.

[24] M. Sathish, B. Viswanathan, R.P. Viswanath, C.S. Gopinath, Chem. Mater.17 (2005) 6349-6353.

[25] H. X. Li, J. X. Li, Y. I. Huo, J. Phys. Chem. B 110 (2006) 1559-1565.

[26] R. Gomez, T. Lopez, E.OrtizIslas, J. Navrrete, E. Sanchez, F. Tzompantzi,X. Bokhimi, J. Mol.Catal. A: Chem.193 (2003) $217-226$.

[27] Y. Wang, Y. Meng, H. Ding, Y. Shan, X. Zhao, X. Tang, J. Phys. Chem. C 112 (2008) 6620-6626.

[28] X. Chen, C. Burda, J. Phys. Chem. B 108 (2004) 15446-15449.

[29] M. S. Wong, H. P. Chou, T. S. Yang, Thin solid films 494 (2006) 244-249.

[30] T. Ohno, T. Mitsui, M. Matsumura, Chem. Lett. 32 (2003) 364-368

[31] X. Z. Shen, J. Guo, Z. C. Liu, S. M. Xie, Appl. Surf. Sci. 254 (2008) 4726-4731.

[32] T. Ma, M. Akiyama, E. Abe, I. Imai, Nano lett. 5 (2005) 2543-2547.

[33] S. Sakthivel, M. Janczarek, H. Kisch, J. Phys. Chem. B 108 (2004) 19384-19387.

[34] N. C. Saha, H. G. Tompkins, J. Appl. Phys. 72 (1992) 3072-3079.

[35] C. Di Valentin, G. Pacchioni, A. Selloni, S. Livraghi, E. Giamello, J. Phys. Chem. B 109 (2005) 11414-11419.

[36] V. N. Kuznetsov, N. Serpone, J. Phys. Chem. C 113 (2009) 15110-15123.

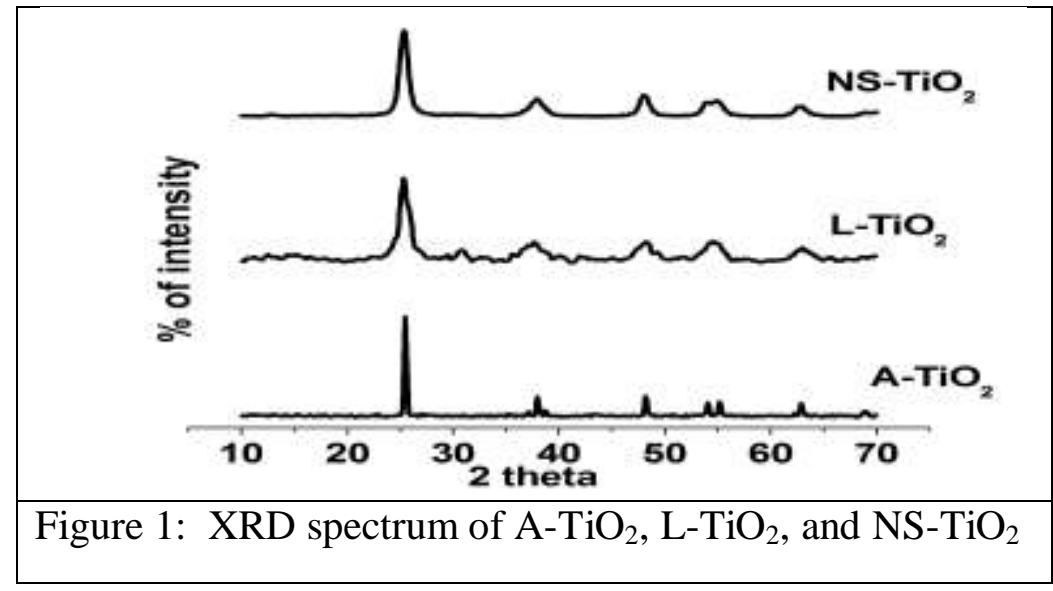




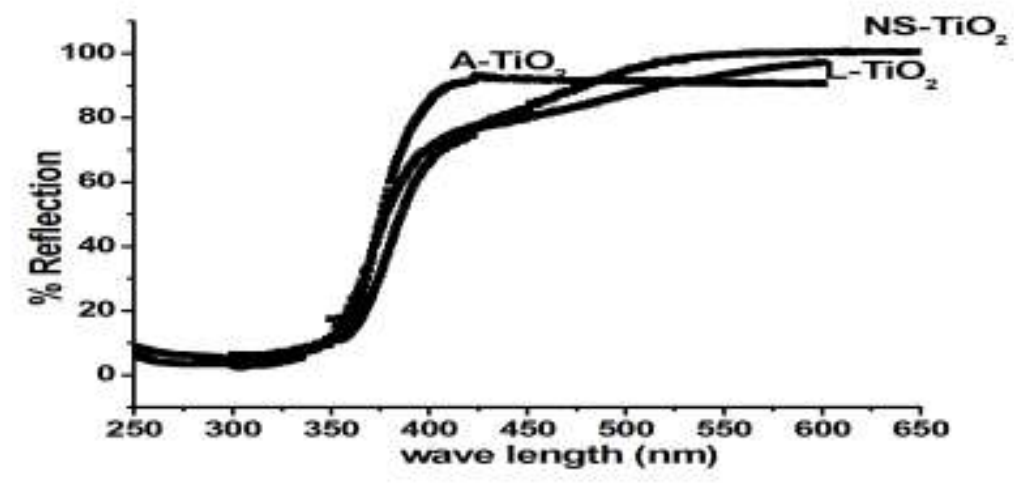

Figure 2: UV-Visible DRS spectrum of A-TiO $2, \mathrm{~L}^{-\mathrm{TiO}_{2}}$, and $\mathrm{NS}-\mathrm{TiO}_{2}$
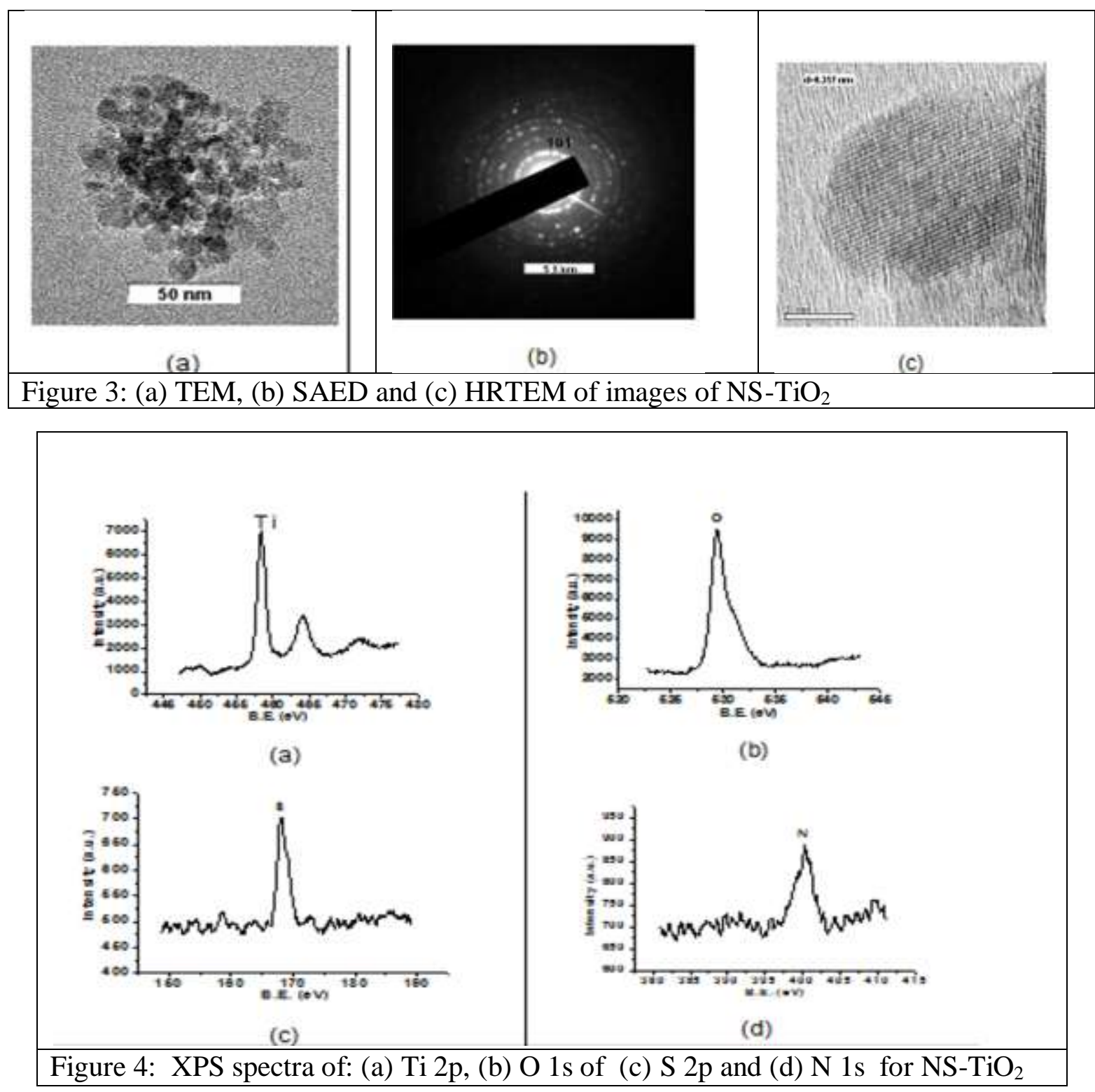


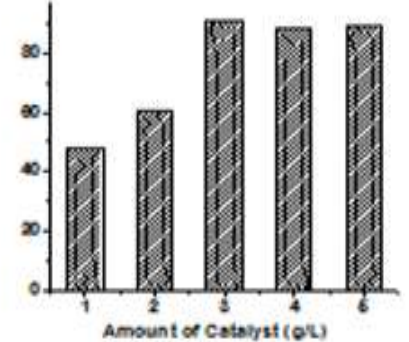

(a)

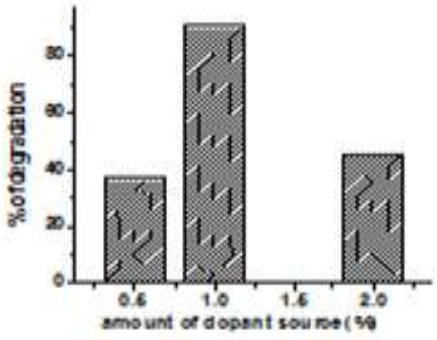

(b)

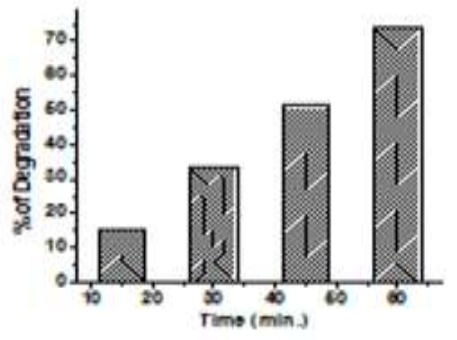

(c)

Figure 5: Per cent of degradation of 2,4-D against (a) amount of catalyst, (b) amount of dopant source and (c) time

Table 1 Weight $\%$ of N and S, crystallite size, Band gap and Surface area of the catalysts

\begin{tabular}{|c|c|c|c|c|c|}
\hline \multirow{2}{*}{ Catalyst } & \multicolumn{2}{|c|}{ Weight $\%$ of dopant ${ }^{\mathrm{a}}$} & \multirow{2}{*}{$\begin{array}{c}\text { Crystallite size } \\
\text { (nm) }\end{array}$} & \multirow{2}{*}{$\begin{array}{c}\text { Band gap } \\
(\mathrm{eV})\end{array}$} & \multirow{2}{*}{$\begin{array}{c}\text { S.A BET } \\
\left(\mathrm{m}^{2} / \mathrm{g}\right)\end{array}$} \\
\hline & Nitrogen & Sulphur & & & \\
\hline $\mathrm{NS}-\mathrm{TiO}_{2}$ & 0.18 & 1.14 & 10.02 & $2.33 \& 3.14$ & 100 \\
\hline $\mathrm{L}-\mathrm{TiO}_{2}$ & 0.0 & 0.0 & 11.6 & 3.08 & 85 \\
\hline $\mathrm{A}-\mathrm{TiO}_{2}$ & 0.0 & 0.0 & 36.14 & 3.14 & 12 \\
\hline
\end{tabular}

a- Weight percent obtained from CHN analysis

b- $\quad$ Crystalline size calculated from XRD

c- $\quad$ Band gap calculated from UV-Visible DRS spectrum

d- $\quad$ Surface area calculated from BET method.

Table 2 Atomic ratios derived from XPS data

\begin{tabular}{|c|c|c|c|c|c|c|c|c|c|c|c|c|}
\hline \multicolumn{3}{|c|}{$\begin{array}{c}\text { Ti 2p3/2 peak } \\
(5.22)^{\mathrm{a}}\end{array}$} & \multicolumn{3}{|c|}{$\begin{array}{l}\text { O 1s peak } \\
(2.85)^{\mathrm{a}}\end{array}$} & \multicolumn{3}{|c|}{$\begin{array}{c}\text { N 1s peak } \\
(1.74)^{\mathrm{a}}\end{array}$} & \multicolumn{3}{|c|}{$\begin{array}{l}\text { S 2p peak } \\
(1.25)^{\mathrm{a}}\end{array}$} & \multirow{2}{*}{$\begin{array}{c}\text { Ti:O:N: } \\
\text { S }\end{array}$} \\
\hline 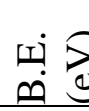 & $\sum_{i}^{1} \sum$ & 禀 & ن & $\sum_{i}^{1} \sum \sum_{9}$ & 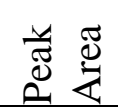 & 实 & $\sum_{\Sigma}^{T}$ & 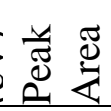 & i் & $\sum_{1}^{I} \Sigma^{2}$ & 崖 & \\
\hline $\begin{array}{l}458 . \\
4\end{array}$ & 1.13 & $\begin{array}{l}7194 . \\
8\end{array}$ & $\begin{array}{l}529 . \\
4\end{array}$ & 1.05 & $\begin{array}{l}7069 . \\
2\end{array}$ & $\begin{array}{l}400 . \\
2\end{array}$ & 2.41 & $\begin{array}{l}485 . \\
9\end{array}$ & $\begin{array}{l}168 \\
3\end{array}$ & 1.70 & $\begin{array}{l}43 \\
5\end{array}$ & $\begin{array}{l}1: 1.86: \\
0.09: 0 \\
18\end{array}$ \\
\hline
\end{tabular}

Table 3 Comparison studies of all the catalyst

\begin{tabular}{ccccc}
\hline \multirow{2}{*}{ Studies } & \multicolumn{4}{c}{ \% of Degradation } \\
\cline { 2 - 5 } & $\mathrm{NS}^{-\mathrm{TiO}_{2}}$ & $\mathrm{~L}^{-\mathrm{TiO}_{2}}$ & $\mathrm{~A}-\mathrm{TiO}_{2}$ & Without Catalyst \\
\hline $\begin{array}{c}\text { Visible light } \\
(420-630 \mathrm{~nm})\end{array}$ & 90.7 & 30.0 & 29.3 & 0.0 \\
\hline $\begin{array}{c}\text { UV light } \\
(280-400 \mathrm{~nm})\end{array}$ & 40.8 & 63.9 & 93.3 & \\
\hline
\end{tabular}

